\title{
Look beyond the impact factor
}

\author{
Hindrik Mulder ${ }^{1}$
}

Published online: 4 August 2021

(C) The Author(s), under exclusive licence to Springer-Verlag GmbH Germany, part of Springer Nature 2021

As Editor-in-Chief of Diabetologia, I am pleased and proud to bring you the news that the impact factor of the journal has broken through the barrier of 10 for the first time: our 2020 impact factor is $10.1^{\mathrm{a}}$. Being new to the role, I take no credit for this: this achievement is a testament to the hard work of my predecessor, Professor Sally Marshall, the worldwide team of editors and the editorial staff of the journal, as well as of all the labour that has gone into the excellent publications that form the journal. Our authors, reviewers and editors work exceedingly hard to provide the scientific community with the most important, novel and relevant research on diabetes and its complications and I will strive to ensure this continues under my editorship.

The impact factor is an index thought to reflect how well a journal selects and disseminates its content. It is calculated from the ratio of citations and published articles during a given time period. I will not reiterate abundant and lengthy discussions about whether the impact factor is an appropriate index of journal quality or not. Needless to say, a multitude of factors will affect the numerator and denominator of the ratio without necessarily reflecting any parameter of quality. However, whether we like it or not, the impact factor plays an important role when journals are ranked, and influences an author's choice of where to publish their work.

Even though the journal has been awarded a very high impact factor and is consolidating its standing in the field of diabetes and metabolism, my sincere hope is that the community will see beyond the impact factor of the journal.

Diabetologia prides itself on the highest possible standards and a personalised approach from the moment

${ }^{\mathrm{a}} \mathrm{We}$ acknowledge that this figure is probably artificially inflated this year as Clarivate transition from using the date of print publication of an article to the date of online publication in the impact factor calculation

Hindrik Mulder

hindrik.mulder@med.lu.se

1 Unit of Molecular Metabolism, Lund University Diabetes Centre, Malmö, Sweden authors submit until accepted articles have been published. Papers that are clearly outside the remit of the journal or that are not sufficiently novel are triaged quickly, allowing authors to submit elsewhere without delay. We strive to return a first decision on externally reviewed papers within a month of submission, and will communicate any delays to authors. We could not do this without the support of our $1000+$ referees and pool of statistical experts, who give up their precious time to provide constructive feedback. We use software to check for text overlap and we screen images to try and identify inappropriate manipulation of blots and micrographs to ensure that the material we publish is trustworthy. The Scientific Integrity Panel of the EASD is on hand to advise the journal if misconduct is suspected. Our highly competent copyeditors and proofreaders check accepted papers with a fine-tooth comb, identifying issues that may have been missed by authors, referees and editors. Our goal is to ensure that the articles we publish are as good as they possibly can be.

The journal has in place a structured procedure to identify hot topics for review articles, using the collective expertise of our reviews editor, associate editors and editorial board. We publish annual special issues dedicated to timely and important topics, commissioning review articles from leaders in the field, and we showcase a selection of these in the Diabetologia symposium at the annual EASD meeting.

As a transformative journal, committed to transitioning to a fully open access journal, Diabetologia can offer authors many options when it comes to open access publication and compliance with funders' mandates. Our publisher, Springer Nature, has a number of 'read and publish' deals, which permit authors at participating institutions to publish with open access at no additional charge. Just over $40 \%$ of articles were published with open access in 2020 and in the same year Diabetologia articles were downloaded over 3.25 million times. We highlight all published articles on social media platforms and commission press releases and conduct interviews with authors for a smaller fraction of articles. 
All these efforts go far beyond the impact factor of a journal.

Diabetologia is as prestigious now as when I was a $\mathrm{PhD}$ student in the early nineties. We will ensure it remains a pillar of diabetes research by developing the journal to serve the research community as best we can. Impact factors may rise and fall but the reputation of Diabetologia is solid.

Publisher's note Springer Nature remains neutral with regard to jurisdictional claims in published maps and institutional affiliations. 